\title{
Application of PLGA-ion exchange resin microcapsules of sulfasalazine for embolization therapy
}

\author{
Ameer Z. Wohaib, Nidhal K. Maraie, and Gaith A. Jassimb
}

a Department of Pharmaceutics, College of Pharmacy, Mustansiriyah University, Baghdad, Iraq

b Department of Pharmacology, College of Pharmacy, Mustansiriyah University, Baghdad, Iraq.

Correspondence to Ameer Z. Wohaib (email: azw_alw@yahoo.com).

(Submitted: 23 August 2019 - Revised version received: 08 September 2019 - Accepted: 22 September 2019 - Published online: 26 October 2019)

\begin{abstract}
Objective This work involves preparation and evaluation (in vitro/in vivo) of microcapsules containing sulfasalazine-ion exchange resin complex (resinate) to induce emboli for treatment of solid cancer.

Methods The drug-resin complex (resinate) had been optimized by using drug:resin ratio (1:8), by suspending the resin in sulfasalazine aqueous solution with at $400 \mathrm{rpm}$ for $120 \mathrm{~min}$ at $50^{\circ} \mathrm{C}$. For controlling the release of drug, microencapsulation for the resinate was applied where 21 formulas with different resinate:poly(lactic-co-glycolic acid) ratios 2:1, 1:1 and 1:2 were prepared by solvent evaporation method to study the effect of different variables including resinate:polymer ratio, stirring speed, effect of temperature and aqueous phase volume on microencapsulation efficiency and percent of yield.

Results The in vitro release study for the prepared resinate, which had $72 \%$ entrapment efficiency, showed $80.992 \%$ of drug released within 15 min and the release continued until $99.83 \%$ within 75 min formula was found to be F19 had $76.70 \%$ encapsulation efficiency and $89.40 \%$ yield. The in vitro release study for selected formula showed that $32 \%$ of drug released within $1 \mathrm{~h}$ and $78 \%$ of drug released within 20 days and the release continued up to $96 \%$ within 45 days indicating a controlled release manner with spherical microcapsule of $595 \mu$ m. The preliminary in vivo work using rabbits showed instant occlusion of the central auricular artery of the rabbit ear leading to ischemia within 3 days that continued to the end of study period.

Conclusion This work show the suitability of microcapsules size to prevent blood flow and forming embolization with controlling release of the drug that may treat the solid tumor.

Keywords embolization therapy, sulfasalazine, DEAE sephadex A-25 ion exchange resin, PLGA coated microcapsules
\end{abstract}

\section{Introduction}

Controlled release dosage form is a dosage forms that release the drug continuously in predetermined pattern for a fixed period of time, either systemically or locally to specified target organ. ${ }^{1}$ It occurs when the active constituents and polymer both combined in such manner that the release from the bulk materials was pre-designed; its role is to alter the pharmacokinetics and or pharmacodynamics of pharmacologically active moieties by using novel drug delivery system or by modification of molecular structure or its physiological parameters. ${ }^{2}$ Embolization technique is a technique in which an occlusive drug is delivered through a catheter to block flow within a targeted blood vessel. It is performed for many medical conditions such as discontinue bleeding from a hemorrhagic ulcer or to tumor by blocking its blood supply. ${ }^{3}$ Ion exchange resin microspheres can be used to induce emboli after loading with the suitable drug and in order to obtain the suitable particle size to block the blood supply microencapsulation technique can be applied. ${ }^{4}$ The polymer used as a coated material is poly(lactic-co-glycolic acid) (PLGA) which is a family of FDA-approved biodegradable polymers that are physically strong and highly biocompatible and have been extensively studied as sustained delivery vehicles for drugs. ${ }^{5}$ Coating (microencapsulation) of the microspheres loaded drug like drug-resin complex (DRC) provided better control on the release of the drug by utilizing rate-controlling membrane that can modify the action of the therapeutic emboli for a longer time. ${ }^{6}$

Sulfasalazine is tasteless, odorless, brownish-yellow powder with $542^{\circ} \mathrm{C}$ melting point. It is indicated in the treatment of mild to moderate ulcerative colitis, it is also indicated in rheumatoid arthritis, juvenile rheumatoid arthritis, Crohn's disease and psoriatic arthritis. ${ }^{7}$ Sulfasalazine has a potent inhibitory property on system $\left(X_{c}^{-}\right)$since it markedly reduced cystine uptake, glutathione levels, growth and viability of human cancer cells. ${ }^{8}$

The aim of this work is to prepare and evaluation (in vitro/ in vivo) microcapsules containing sulfasalazine-ion exchange resin complex (resinate) to induce emboli for treatment of solid cancer through cutting off blood supply to area and slowly release the drug for a long period enough to treat the disease, to be used as alternative to surgery, chemotherapy and radiotherapy that had serious side effects.

\section{Materials and Methods}

\section{Materials}

Sulfasalazine purchased Hyperchem, China, DEAE-sephadex A25 from Pharmacia Pharmaceutical company, Sweden, PLGA [lactic acid:glycolic acid (85:15)] from Advanced Biomedical Technology, Taiwan.

\section{Methods}

\section{Preparation of drug-resin complex}

The DRC had been prepared in our laboratory but it required further optimization therefore specific amount of resin (DEAE sephadex A-25) was used to prepare a drug:resin ratio (1:8) by suspending the resin in sulfasalazine aqueous solution with at $400 \mathrm{rpm}$ for $120 \mathrm{~min}$ at $50^{\circ} \mathrm{C}$ using hot plate magnetic stirrer then the obtained residue allowed to dry in a hot air oven at $40^{\circ} \mathrm{C}$ overnight. ${ }^{9}$ The drug entrapment efficiency was 
determined by analyzing the supernatant obtained for the free drug by measuring its UV absorbance at $359 \mathrm{~nm}$, the amount of sulfasalazine entrapped was determined according to this equation. ${ }^{10}$

$\left[\right.$ Entrapment efficiency $\left.(\mathrm{EE})=\frac{\text { Entrapped drug content }}{\text { Initial drug content }}\right]$

\section{In vitro Dissolution Study for the Prepared Drug-resin Complex}

The release of the drug from the prepared DRC (resinate; $1: 8$ ) was studied using dissolution apparatus II and $900 \mathrm{ml}$ phosphate buffer ( $\mathrm{pH} \mathrm{7.4)}$ as dissolution medium fixed at $50 \mathrm{rpm}$ stirring speed and $37^{\circ} \mathrm{C}$. Samples $(5 \mathrm{ml})$ were withdrawn at predetermined time, filtered and analyzed using UV spectrophotometer at $359 \mathrm{~nm},{ }^{11}$ the withdrawn samples were replaced by the same of fresh phosphate buffer. ${ }^{12}$

\section{Microencapsulation of the Prepared Drug-resin Complex}

Microcapsules were prepared by solvent evaporation method, as follows:

(a) Aqueous phase: specific amount of the selected resinate (ratio 1:8) was suspended in $300 \mathrm{ml}$ aqueous media containing $50 \mathrm{ml}$ of glycerol in polyvinyl alcohol solution $(0.15 \% \mathrm{w} / \mathrm{v})$.

(b) Organic phase: different amounts of PLGA had been dissolved in $20 \mathrm{ml}$ dichloromethane (DCM).
Then organic phase had been added to the aqueous phase with continuous shaking at $35^{\circ} \mathrm{C}$ for $45 \mathrm{~min}$ (until complete evaporation of DCM). The mixture was filtered and the microcapsules obtained had been washed with sufficient quantity of deionized distilled water and normal hexane to remove any residual organic solvent, and then washed with formaldehyde (5\%) to solidify the coated layer. The prepared microcapsules were dried overnight in a hot air oven at $40^{\circ} \mathrm{C}$. Twenty-one formulas containing different resinate:PLGA ratio 2:1, 1:1 and 1:2 were prepared using different volumes of aqueous phase at different stirring speed and stirring temperature in order to optimize the preparation, ${ }^{13}$ as shown in Table 1.

Encapsulation efficiency and percentage of product yield were the main parameters used to evaluate microencapsulation methods and conditions and they were calculated as the follows: ${ }^{14}$

$$
\begin{gathered}
\text { Encapsulation efficiency }=\frac{\text { Total drug }- \text { Free drug }}{\text { Total drug }} \times 100 \% \\
\text { Percent yield }=\frac{\text { Actual yield }}{\text { Theoretical yield }} \times 100 \%
\end{gathered}
$$

\section{Variables Affecting Percent of Yield and Encapsulation Efficiency of the Prepared Microcapsules}

\section{Effect of Resinate:PLGA Ratio}

The effect of using different ratios of resinate:PLGA (1:2, 1:1 and

\begin{tabular}{|c|c|c|c|c|c|c|c|}
\hline \multirow{2}{*}{$\begin{array}{l}\text { Formula } \\
\text { no. }\end{array}$} & \multirow{2}{*}{$\begin{array}{l}\text { Amount of } \\
\text { resinate (mg) }\end{array}$} & \multicolumn{2}{|c|}{ Organic phase } & \multirow{2}{*}{$\begin{array}{l}\text { Aqueous } \\
\text { phase (ml) }\end{array}$} & \multirow{2}{*}{$\begin{array}{c}\text { Stirring } \\
\text { temperature }\left({ }^{\circ} \mathrm{C}\right)\end{array}$} & \multirow{2}{*}{$\begin{array}{c}\text { Stirring } \\
\text { speed (rpm) }\end{array}$} & \multirow{2}{*}{$\begin{array}{c}\text { Resinate:PLGA } \\
\text { ratio }\end{array}$} \\
\hline & & PLGA (mg) & $\mathrm{DCM}(\mathrm{ml})$ & & & & \\
\hline F1 & 30 & 60 & 20 & 300 & 35 & 600 & $1: 2$ \\
\hline F2 & 30 & 60 & 20 & 400 & 35 & 600 & $1: 2$ \\
\hline F3 & 30 & 60 & 20 & 500 & 35 & 600 & $1: 2$ \\
\hline $\mathrm{F} 4$ & 30 & 30 & 20 & 300 & 35 & 600 & $1: 1$ \\
\hline F5 & 30 & 30 & 20 & 400 & 35 & 600 & 1:1 \\
\hline F6 & 30 & 30 & 20 & 500 & 35 & 600 & $1: 1$ \\
\hline F7 & 30 & 15 & 20 & 300 & 35 & 600 & $2: 1$ \\
\hline F8 & 30 & 15 & 20 & 400 & 35 & 600 & $2: 1$ \\
\hline F9 & 30 & 15 & 20 & 500 & 35 & 600 & $2: 1$ \\
\hline F10 & 30 & 60 & 20 & 500 & 45 & 600 & $1: 2$ \\
\hline F11 & 30 & 60 & 20 & 500 & 55 & 600 & $1: 2$ \\
\hline F12 & 30 & 30 & 20 & 500 & 45 & 600 & $1: 1$ \\
\hline F13 & 30 & 30 & 20 & 500 & 55 & 600 & $1: 1$ \\
\hline F14 & 30 & 15 & 20 & 500 & 45 & 600 & $2: 1$ \\
\hline F15 & 30 & 15 & 20 & 500 & 55 & 600 & $2: 1$ \\
\hline F16 & 30 & 60 & 20 & 500 & 55 & 700 & $1: 2$ \\
\hline F17 & 30 & 60 & 20 & 500 & 55 & 800 & $1: 2$ \\
\hline F18 & 30 & 30 & 20 & 500 & 55 & 700 & $1: 1$ \\
\hline F19 & 30 & 30 & 20 & 500 & 55 & 800 & $1: 1$ \\
\hline F20 & 30 & 15 & 20 & 500 & 55 & 700 & $2: 1$ \\
\hline F21 & 30 & 15 & 20 & 500 & 55 & 800 & $2: 1$ \\
\hline
\end{tabular}
$2: 1$ ) on the encapsulation efficiency and percent of yield of the 
prepared microcapsules was studied using F1, F4 and F7 using $300 \mathrm{ml}$ aqueous medium, $600 \mathrm{rpm}$ stirring speed at $35^{\circ} \mathrm{C} .{ }^{15}$

\section{Effect of Aqueous Phase Volume}

The effect of volume of aqueous phase (300, 400 and $500 \mathrm{ml})$ on the encapsulation efficiency and percent of yield of the prepared microcapsules from each resinate:PLGA ratios $(2: 1,1: 1$ and 1:2) was studied using formulas F1-F9.15

\section{Effect of Temperature}

The effect of temperature $\left(35,45\right.$ and $\left.55^{\circ} \mathrm{C}\right)$ on encapsulation efficiency and percent of yield of the prepared microcapsules from each resinate:polymer ratios (2:1, 1:1 and 1:2) was studied using formulas F3, F6, F9-F15, keeping $500 \mathrm{ml}$ aqueous phase and $600 \mathrm{rpm}$ stirring speed. ${ }^{16}$

\section{Effect of Stirring Speed}

The effect of different stirring speeds $(600,700$ and $800 \mathrm{rpm})$ on the encapsulation efficiency and percent of yield of the prepared microcapsules from each resinate:PLGA ratios (2:1, 1:1 and 1:2) was studied using formulas F11, F13, F15-F21 with $500 \mathrm{ml}$ aqueous phase and temperature $55^{\circ} \mathrm{C} .{ }^{17}$

\section{In vitro Dissolution Studies for the Selected Prepared Microcapsules}

For each resinate:PLGA ratio, the best formula of microcapsules was selected depending on entrapment efficiency and percent of yield and they were F17, F19 and F21. The release of drug from selected formulas were measured by modified dissolution method using hot plate magnetic stirrer at $100 \mathrm{rpm}$ and $40 \mathrm{ml}$ phosphate buffer $(\mathrm{pH} 7.4)$ dissolution medium volume at $37^{\circ} \mathrm{C}$ Certain amount from each formula (equivalent to $3.2 \mathrm{mg}$ of sulfasalazine) were placed in dialysis membrane $(3000 \mathrm{Da})$ sealed and introduced in $40 \mathrm{ml}$ of phosphate buffer ( $\mathrm{pH}$ 7.4). Samples $(1 \mathrm{ml})$ were withdrawn at predetermine time and diluted as need by fresh phosphate buffer ( $\mathrm{pH}$ 7.4), filtered and analyzed using a UV spectrophotometer at $359 \mathrm{~nm},{ }^{18}$ the withdrawn samples were replaced by the same volume of fresh phosphate buffer. ${ }^{12}$

\section{Particle Size Analysis}

The ion exchange resin, selected resinates and selected microcapsules formula (F19) each one separately have been examined using laser diffraction particle size analyzer. The particles was suspended in distilled water and characterized by volume and number distribution using laser diffraction and polarization intensity differential scattering. ${ }^{19}$

\section{Morphological Characterization}

The morphological characterization of the selected microcapsules formula (F19) was carried out using scanning electron microscopy (SEM) together with DEAE sephadex A-25 microspheres and the selected resinate. ${ }^{20}$

\section{In vitro Degradation Study}

The in vitro degradability of PLGA coat of the selected microcapsules formula (F17) was assessed using fresh human serum. Three samples (20 mg) of (F17) were suspended separately in $5 \mathrm{ml}$ of human serum and incubated at $37^{\circ} \mathrm{C}$ for 10,20 and 30 days. Sample at each interval has been centrifuged at $1200 \mathrm{rpm}$ for $5 \mathrm{~min}$ and the sediment was washed by deionized distilled water then dried at hot air oven overnight at $40^{\circ} \mathrm{C}$ and examined under SEM. ${ }^{2}$

\section{Preliminary in vivo Test for Embolization Property}

Two rabbits were used to evaluate the embolization property for selected microcapsules formula (F19), the rabbits ears had been prepared for injection by wiping with sterile tissue then (24G) cannula had been inserted in ear central artery through which $3 \mathrm{ml}$ suspension containing ( $30 \mathrm{mg}$ ) of sterile microcapsules (F19) was injected slowly. ${ }^{22,23}$

\section{Results and Discussion}

\section{Preparation of Drug-Resin Complex}

Sulfasalazine is a weak acid for which a weak base anion exchange resin is helpful for preparation of DRC. DEAE sephadex A-25 is one type of the anion exchange resins, which is a weak base in nature and it is biocompatible so it is suitable for formation of complex with sulfasalazine. ${ }^{24}$ DRC was prepared previously in our laboratory but it needs further optimization, therefore in this study DRC 1:8 was prepared and its entrapment efficiency was $72 \%$ which is higher than lower drug:resin ratio since the increase in the amount of resin lead to increase in the number of chemical equivalent that available for ionic exchange per unit weight or volume of resin..$^{25}$

\section{In vitro Dissolution Study for the Prepared Drug-Resin Complex}

Figure 1 shows the cumulative percent of drug release for the prepared drug:resin ratio (1:8). The results showed that the percentage of sulfasalazine released within $15 \mathrm{~min}$ at phosphate buffer ( $\mathrm{pH} 7.4$ ) was $80.992 \%$, and the release continued up to $99.83 \%$ within $75 \mathrm{~min}$, this may be due to the fact that the complex will release the drug only when it is replaced by the ions which have the same charge after hydration of DRC by the medium. The ionic exchange may reach equilibrium, and this depend on the ionic constitution and the fluid volume, also the drug must diffuse from the resin through the internal exchange sites and it mainly depends on the efficient complex formed between the drug and the resin. ${ }^{26}$

\section{Microencapsulation (coating) of Selected Drug-resin Complex (resinate)}

Microencapsulation of the DRC (resinate) is adapted to control release of the drug. Different formulas (21 formulas) of the coated (microencapsulated) resinate had been prepared with different resinate:PLGA ratios, aqueous phase volume, stirring speed and temperature. The encapsulation efficiency and percent of yield were calculated to estimate the best formula.

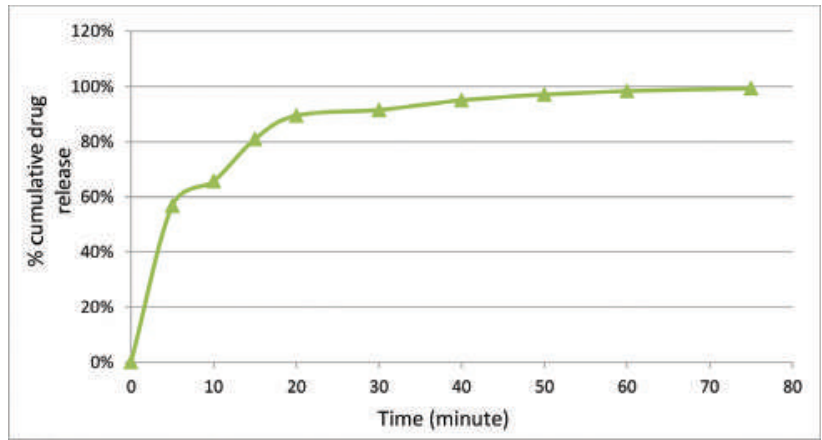

Fig. 1 Cumulative drug release of drug:resin ratio (1:8) with best entrapment efficiency. 


\section{Variables Affecting Percent of Yield and Encapsulation Efficiency of the Prepared Microcapsules}

\section{Effect of Resinate:PLGA Ratio}

The results showed that as PLGA amount was increased (from 2:1 to 1:1) the encapsulation efficiency and percent of yield increased that may be as a result of high viscosity of the continuous phase that may delay the drug diffusion from the resinate and enhance precipitation of PLGA polymer on the surface of the resinate ${ }^{15}$ But the result also showed decrease in encapsulation efficiency with no effect on percent of yield as a PLGA ratio increased from 1:1 to $1: 2$ because the observation indicated that an increase in the polymer concentration increases the entrapment of the drug inside the microsystems but on a high polymer amount it can form a loose network in the matrix which decreased the encapsulation efficiency as the network allows the drug particles to leach out during the microcapsules production ${ }^{27}$ as shown in Fig. 2.

\section{Effect of Aqueous Phase Volume}

The results showed a significant increase in encapsulation efficiency and percent of yield by increasing the volume of aqueous phase that may extract the solvent instantly which lead to fast precipitation of the coating polymer (PLGA) in large volume of continuous phase, ${ }^{28}$ as shown in Fig. 3. Therefore, $500 \mathrm{ml}$ aqueous phase volume was selected for further study.

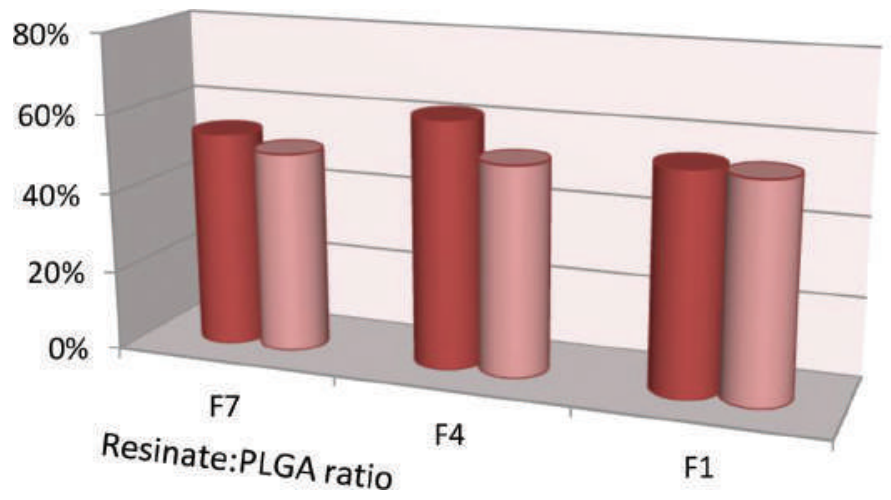

\section{Encapsulation efficiency \\ $\square$ Percent yield}

Fig. 2 Effect of resinate:PLGA ratio on percent of yield and encapsulation efficiency for three prepared formula F1 (ratio 1:2), F4 (ratio 1:1) and F7 (2:1).

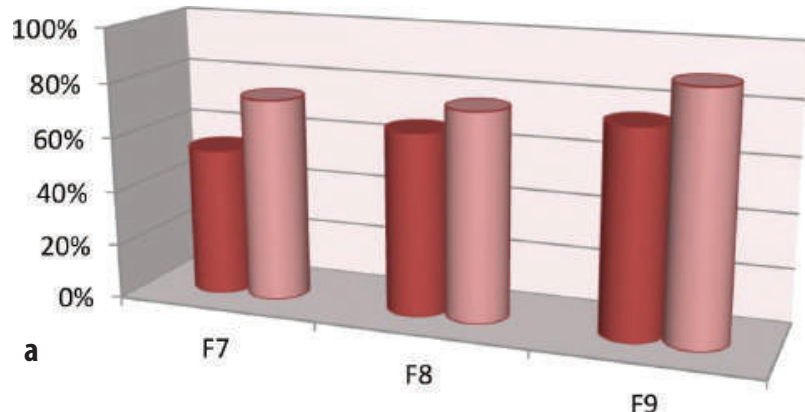

F9
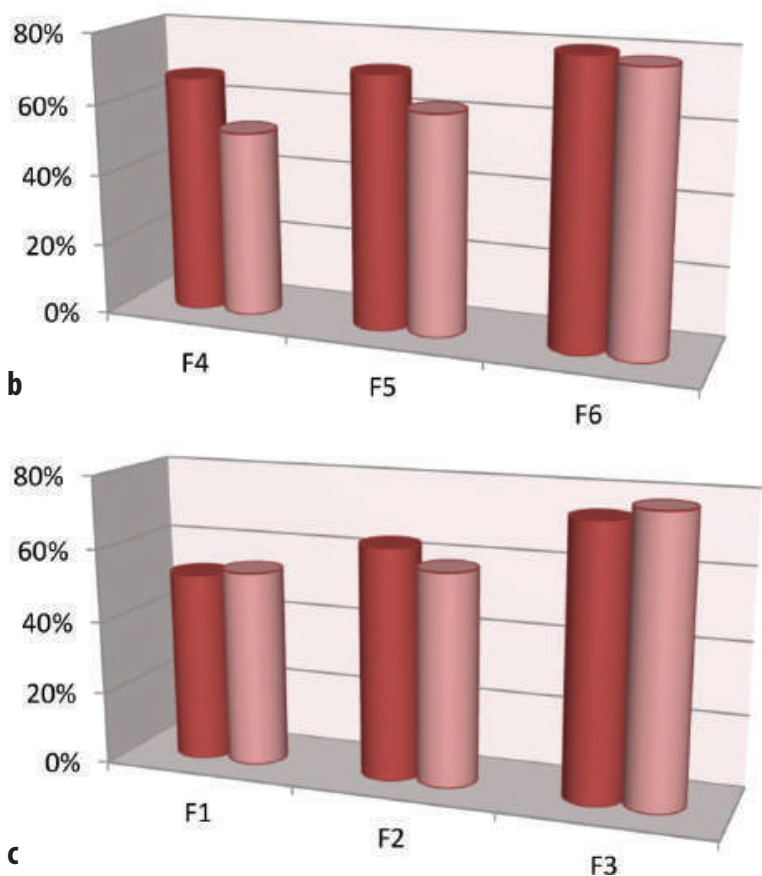

- Percent of drug entrapped

$\square$ Percent of yield

- Percent of drug entrapped

$\square$ Percent of yield

\section{- Percent of drug entrapped}

$\square$ Percent of yield

Fig. 3 Effect of aqueous phase volume on drug encapsulation efficiency and percent of yield for the prepared formula for different resinate:PLGA ratio (a) 2:1, (b) 1:1 and (c) 1:2. 


\section{Effect of Temperature}

It was found that there was a significant increase in the encapsulation efficiency and percent of yield upon increasing the temperature since the high temperature facilitated the evaporation of DCM leading to precipitation of PLGA on the resinate in the dispersed phase, ${ }^{15,17}$ as shown in Fig. 4, therefore, the temperature selected for further study was kept at $55^{\circ} \mathrm{C}$ (using $500 \mathrm{ml}$ aqueous phase volume).

\section{Effect of Stirring Speed}

The results showed as stirring speed increased the percent of yield was significantly increased since the stirring process may enhance the emulsification process. ${ }^{29}$ The results also showed that as the stirring speed increased the encapsulation efficiency decreased (not significantly) that may be due to vortex formation at high agitation rates which resulted in leaching of drug from the resinate..$^{30}$ Therefore, the best stirring speed was $800 \mathrm{rpm}$ (keeping the temperature at $55^{\circ} \mathrm{C}$ and $500 \mathrm{ml}$ aqueous phase volume). Accordingly, for each resinate:PLGA ratio one best formula was selected which had best encapsulation efficiency and percent of yield (F17, F19 and F21), as shown in Fig. 5.

\section{In vitro Dissolution Studies for the Selected Prepared Microcapsules}

The results showed that the percentage of sulfasalazine released from formula (F21) within $1 \mathrm{~h}$ at phosphate buffer $(\mathrm{pH} 7.4)$ was $28 \%$, and the release after 20 day was $81 \%$ which continued up to $98 \%$ within 45 days. On another hand the results showed that the percentage of drug released from formula (F17) within $1 \mathrm{~h}$ was $29 \%$, and the release after 20 days was $70 \%$ which continued up to $93 \%$ within 45 days. While the percentage of drug released from F19 within $1 \mathrm{~h}$ was 32\%, and the release after 20 days was $78 \%$ which continued up to $96 \%$ within 45 days. The initial burst effect may be due to the presence of some drug particles on the surface of the microspheres, which can be considered as a desired effect to ensure the initial therapeutic action of drug. ${ }^{31}$ It was also observed that the drug release from F17 (containing resinate:PLGA ratio 1:2) showed significantly lower drug release than F21 (containing resinate:PLGA ratio 2:1) since the drug release rates decreases as the amounts of polymer increases which may create thicker coat around the particles in the microcapsules. ${ }^{32,33}$ While F19 (containing resinate:PLGA ratio 1:1) showed no significant decrease in drug release in comparison to F21, but F19 showed
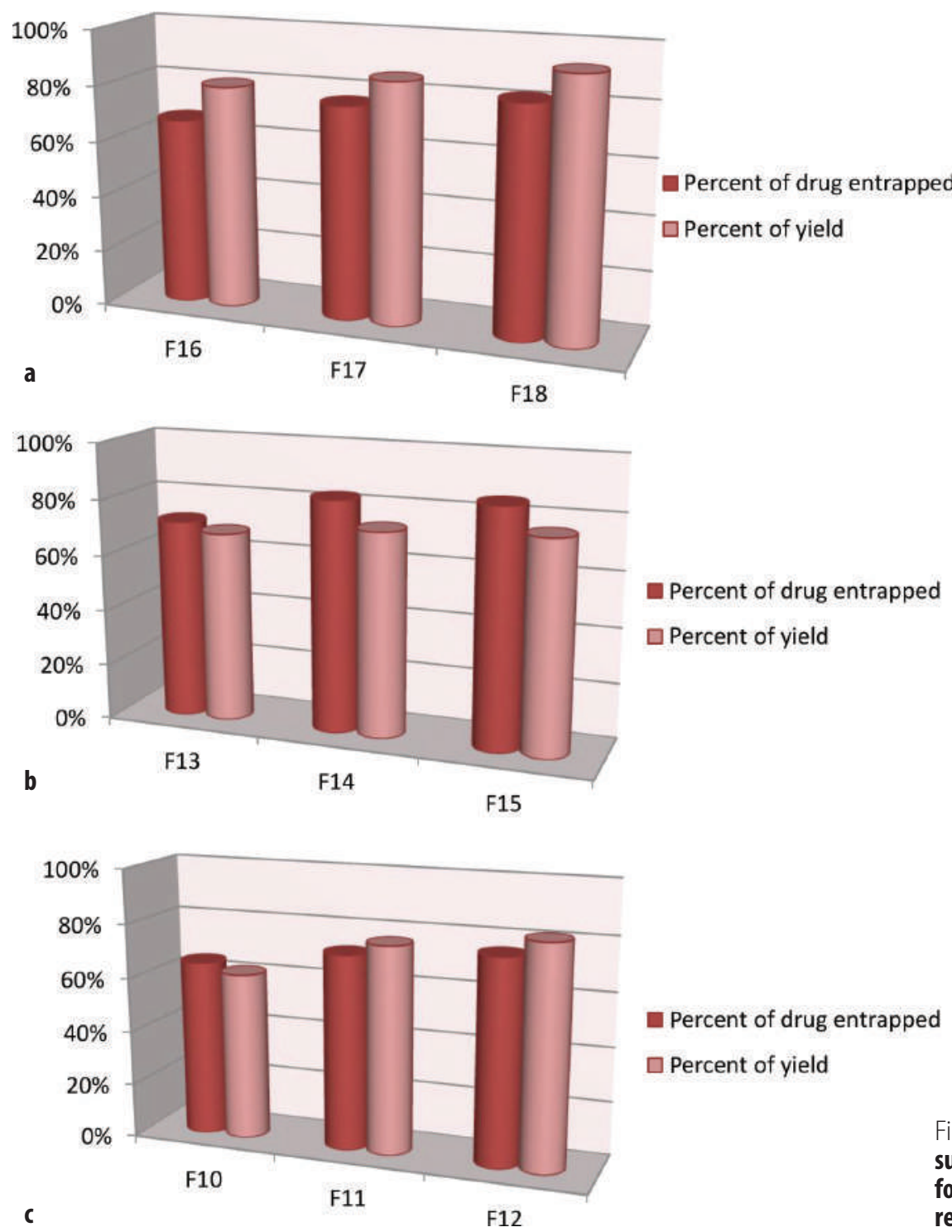

- Percent of drug entrapped

$\square$ Percent of yield

Fig. 4 Effect of temperature on drug encapsulation efficiency and percent of yield for the prepared formula for different resinate:PLGA ratio (a) 2:1, (b) 1:1 and (c) 1:2. 

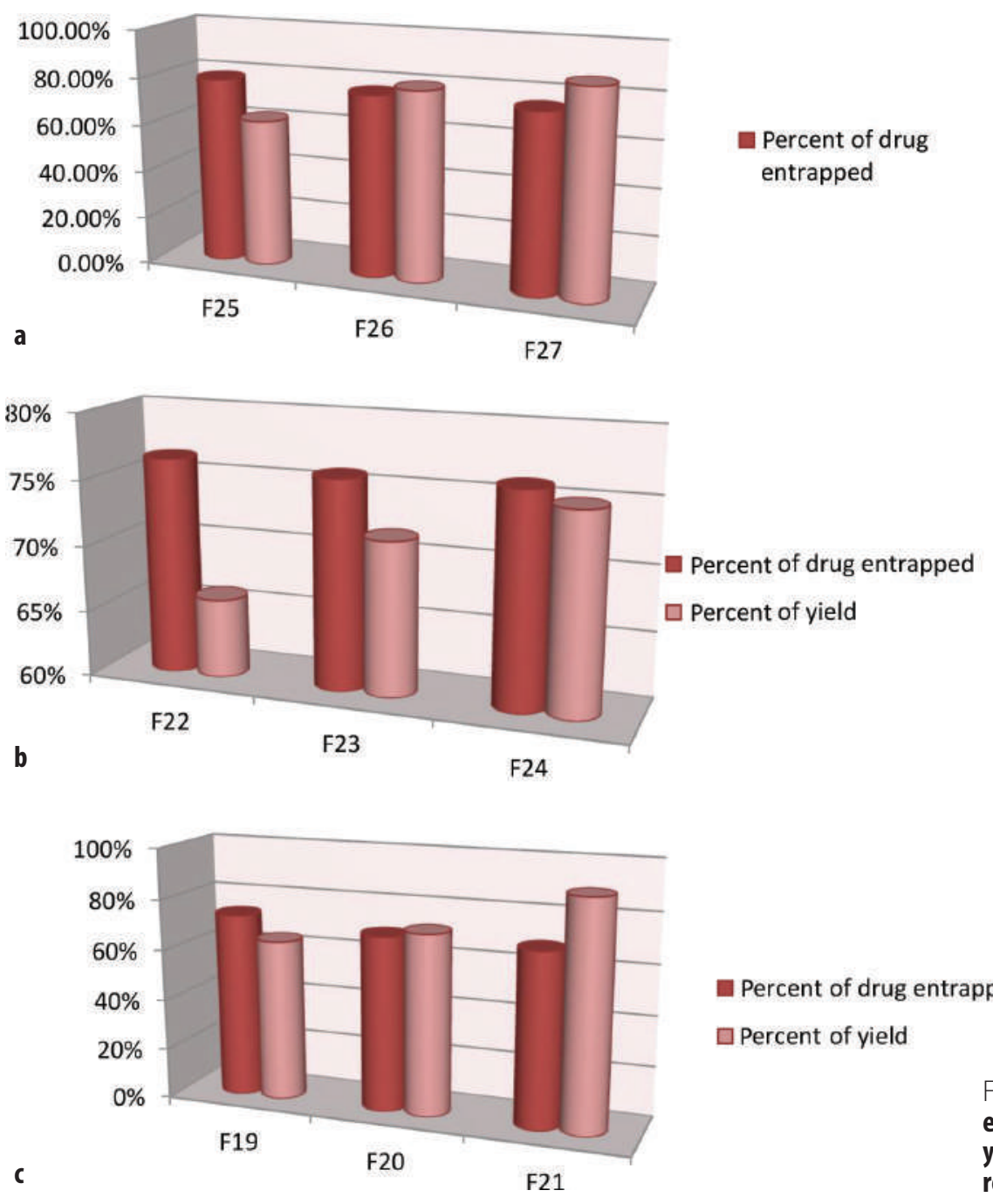

- Percent of drug entrapped

$\square$ Percent of yield
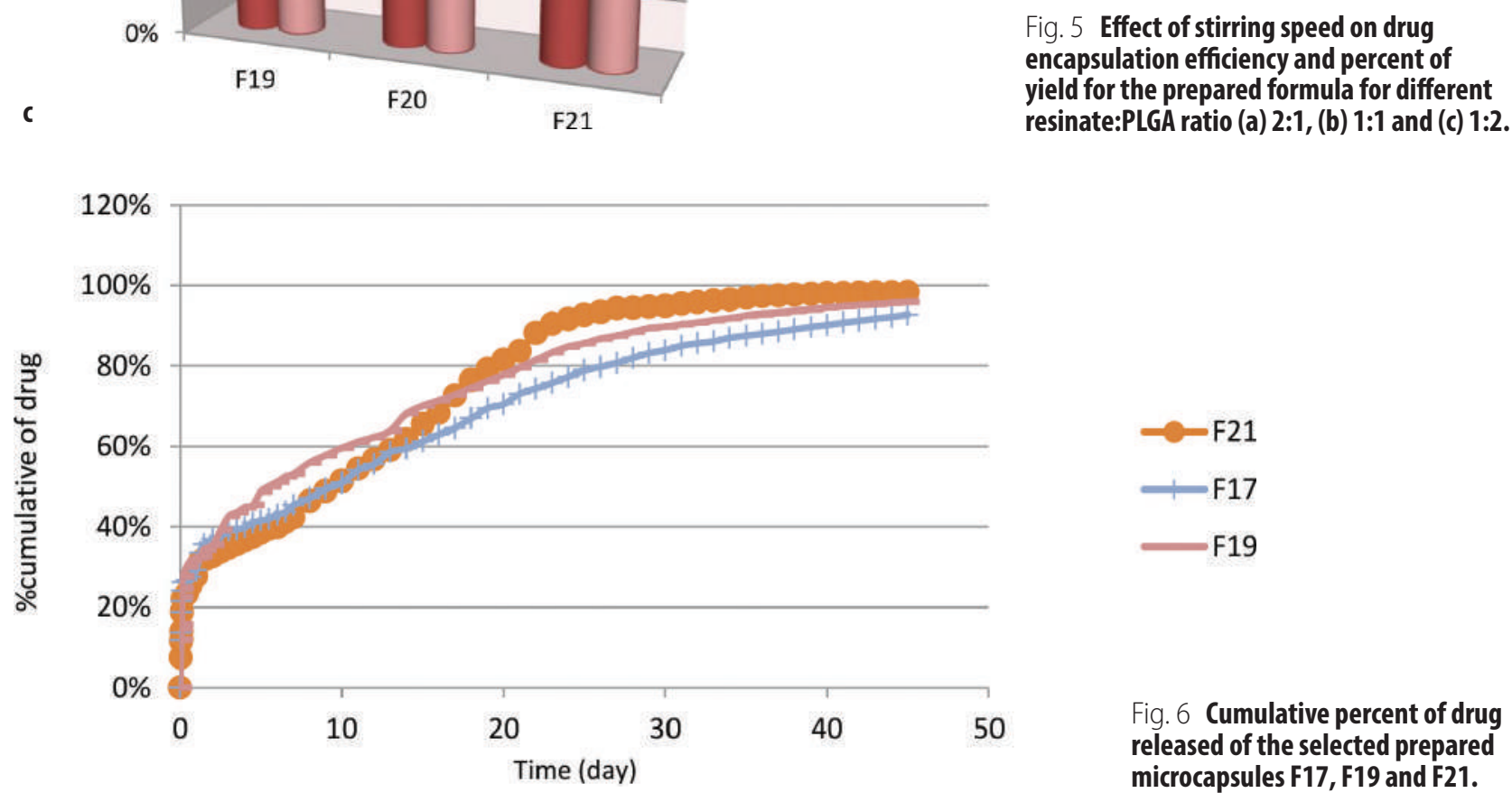

higher encapsulation efficiency and higher percent of yield than F21, therefore, it was selected for further study as shown in Fig. 6.

\section{Particle Size Analysis}

The results showed an increase in particle size of the selected resinate $(588 \mu \mathrm{m})$ and selected prepared microcapsules (F19)
$(595 \mu \mathrm{m})$ in comparison to resin microsphere $(306 \mu \mathrm{m})$. This was due to adsorption of the drug particles on the resin microsphere during DRC process and coating the resinate particles by PLGA polymer in the microencapsulation process. ${ }^{34}$ The result also showed that $90 \%$ of the selected prepared microcapsules (F19) was in $595 \mu \mathrm{m}$ (particle size) which is more suitable for embolization therapy. ${ }^{35}$ 


\section{Differential Scanning Calorimetry}

Figure 7 shows the thermogram of sulfasalazine, DEAE sephadex A-25, selected resinate, selected prepared microcapsules (F19). Sulfasalazine exhibited a sharp exothermic peak at $246.5^{\circ} \mathrm{C}$ indicating the temperature of drug melting. The resin had no detected peaks at the range of temperature used. The DRC showed that the drug exothermic peak was absent indicating the formation of DRC and no drug crystals available. ${ }^{36}$ The result also showed the absence of the drug exothermic peak in the prepared microcapsules indicating that microencapsulation process had no effect on DRC.

\section{Determination of Morphological Characterization}

The results showed the spherical shape of resin microspheres and the resinate showed similar appearance to resin microsphere. The feature of sulfasalazine crystals was not detected indicating formation of drug resin mixture and the drug was dispersed molecularly in the resonates. ${ }^{36,37}$ The results also showed the prepared microcapsules had spherical shape with slightly irregular surface indicating the efficient deposition of PLGA on the surface of resinate with complete coating and no pores referring to the efficient conditions used for optimization of the solvent evaporation method applied ${ }^{38}$ as shown in Fig. 8.

\section{In vitro Degradation Study}

The results showed the gradual biodegradation of PLGA coat of selected formula in human serum where pores formed upon incubation and became more clear with time causing gradual controlled drug release with time accordingly. Similar results obtained with Sorafenib loaded imageable microspheres for embolization where PLGA polymer degradation gave lactic acid and glycolic acid in the biological fluid ${ }^{39,40}$ as shown in Fig. 9. a

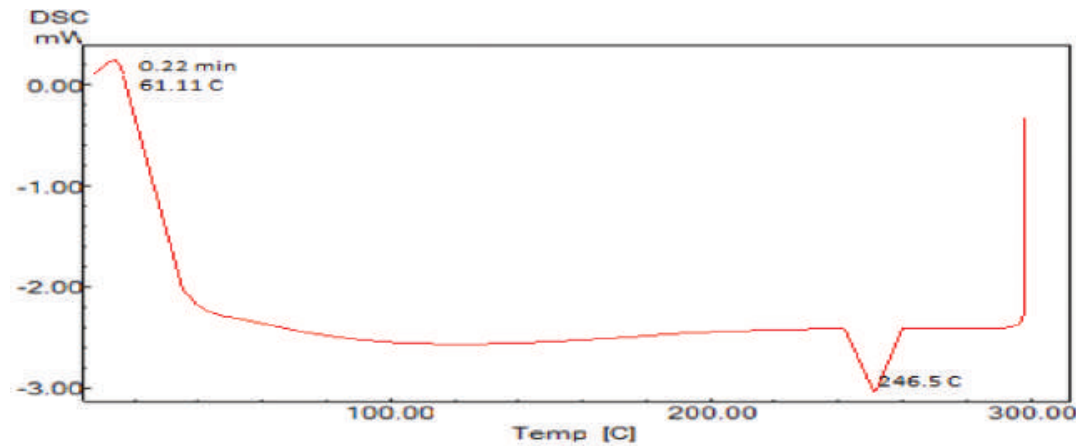

b

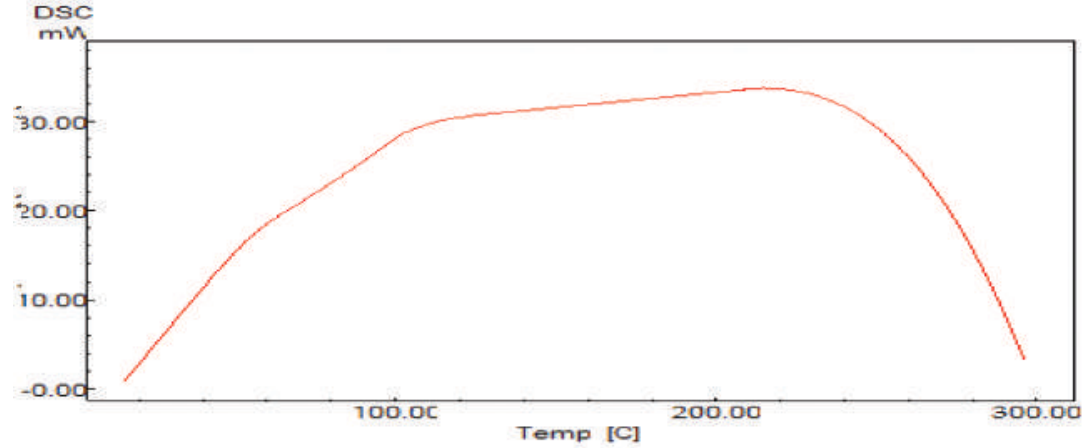

C

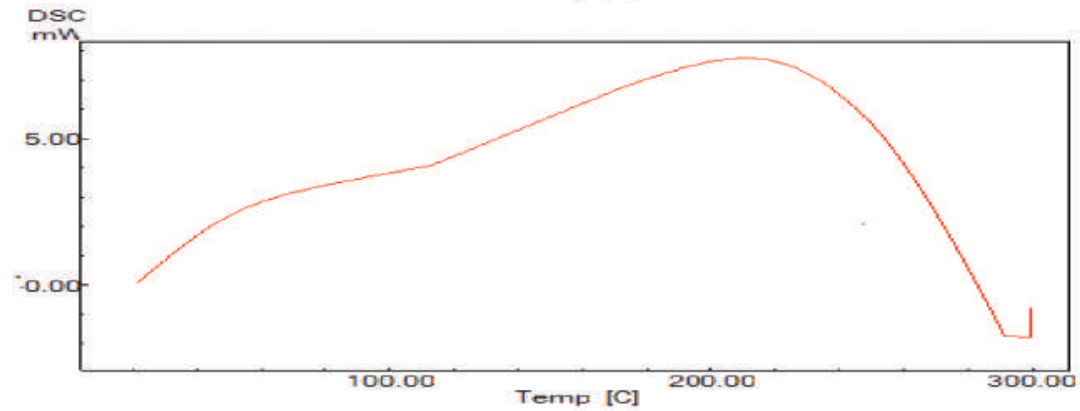

d

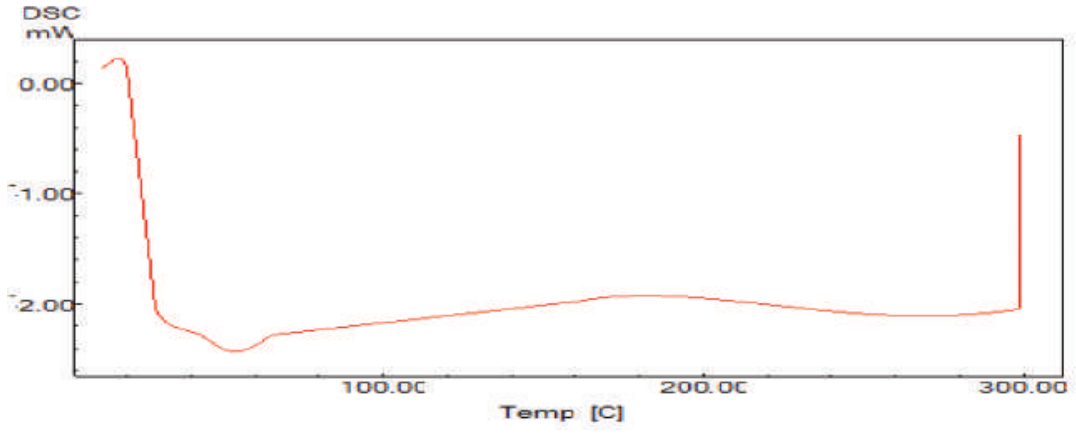

Fig. 7 Differential scanning calorimetry thermogram of (a) sulfasalazine, (b) DEAE sephadex A-25, (c) selected resinate, (d) selected prepared microcapsules (F19). 


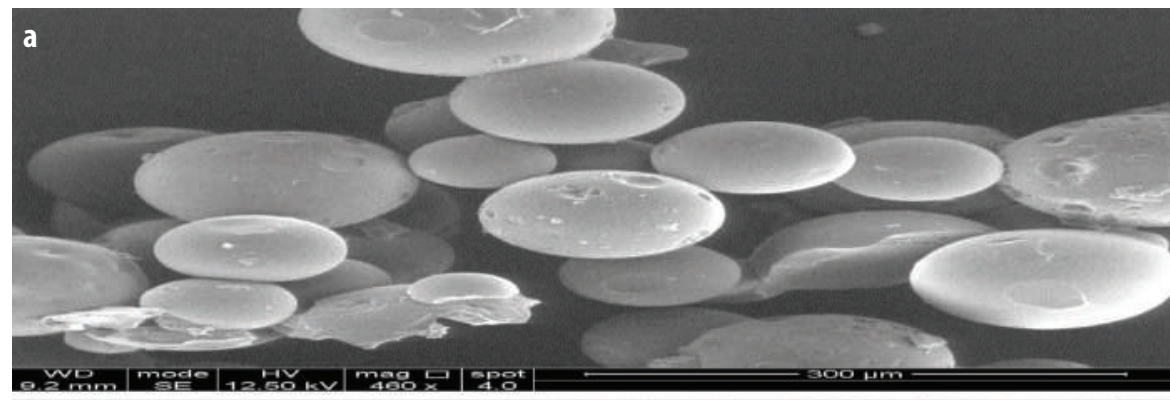

b
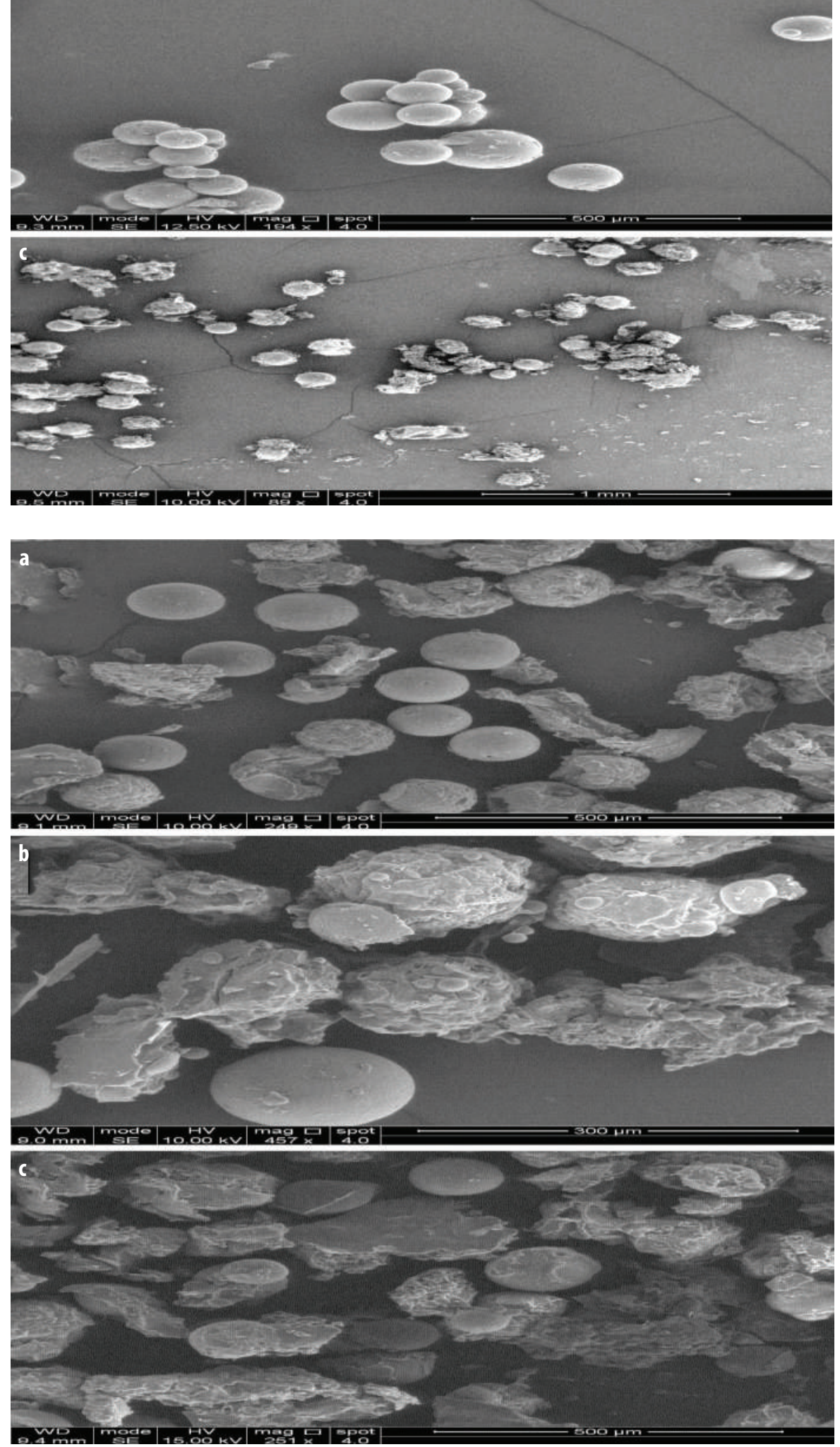

Fig. 9 Incubated samples of selected formula (F19) in human serum at $37^{\circ} \mathrm{C}$ for (a) 10 , (b) 20 and (c) 30 days.
Fig. 8 Scanning electron microscopy (SEM) of (a) DEAE sephadex A-25 microspheres (b) selected resinate (c) selected microcapsules formula (F19). 


\section{Preliminary in vivo Test for Embolization Property}

Figure 10 showed the rabbits ears images at 1, 3, 9, 15, 20 days after selected microcapsules formula (F19) had been injected in the ear central artery to evaluate the embolization property. The results showed the instant occlusion of the central auricular artery near the site of injection causing ischemia in the region within 3 days that continued to the end of the study period. This indicated that the prepared microcapsules having diameter $(595 \mu \mathrm{m})$ aggregated enough to prevent arterial blood flow to the injected area forming embolization. ${ }^{41}$ There was no sign of tissue necrosis upon embolization during the study period.

\section{Conclusion}

This work succeeded in preparation of microcapsules containing sulfasalazine-ion exchange resin and optimized to get spherical microcapsules with $595 \mu \mathrm{m}$ size which was suitable to induce embolization upon in vivo test using rabbits to prevent blood supply to the region as well as controlling drug release for 45 days that may treat the solid tumor to be used as alternative to chemotherapy, radiotherapy and surgery.

\section{Acknowledgment}

The authors would like to thank Mustansiriyah University (www.uomustansiriyh.edu.iq) Baghdad-Iraq for its support in the present work.

\section{Conflicts of Interest}

None.
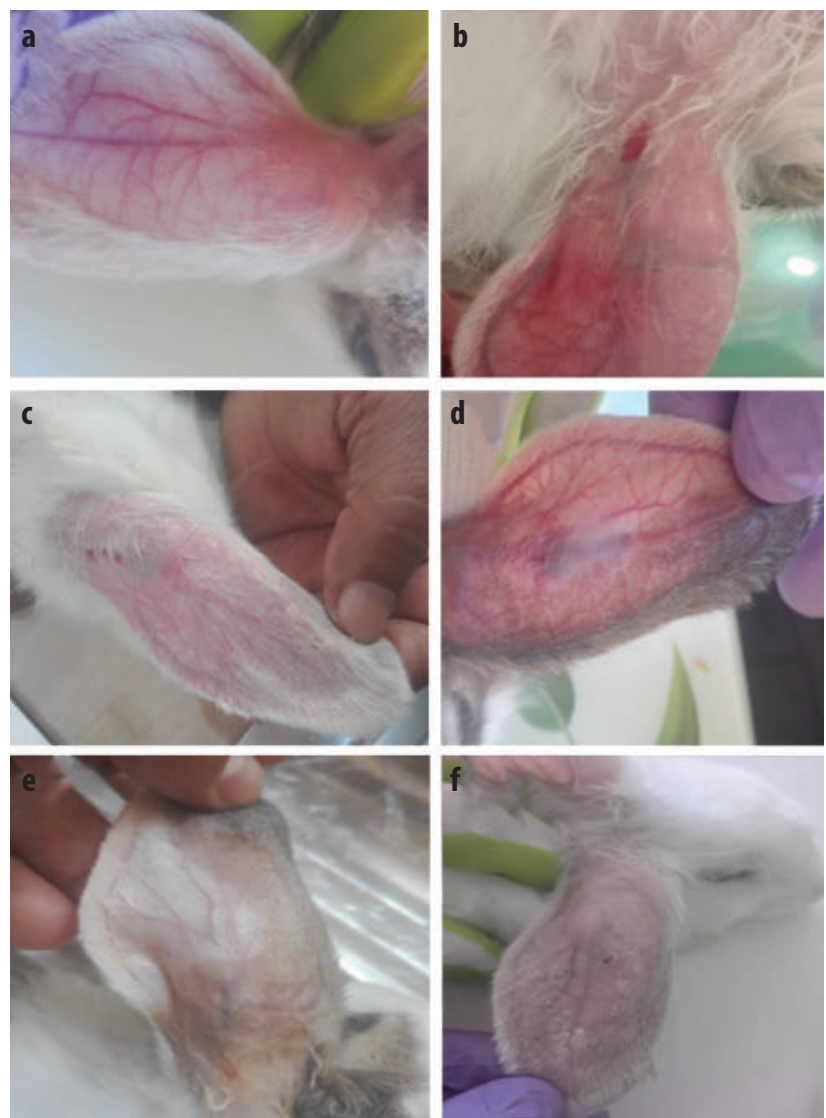

Fig. 10 Rabbits ears which injected with selected prepared microcapsules (F24) after (a) control ears, (b) 1 day, (c) 3, (d) 9, (e) 15 and (f) 20 days.

\section{References}

1. Gahlyan M, Jain S. Oral controlled release drug delivery system- a review. PharmaTutor. 2014;2:170-178.

2. Nidhi P, Anamika C, Twinkle S, Bhakta Mehul S, Hitesh J, Umesh U. Controlled drug delivery system: a review. Indo Am J Pharm Sci. 2016;3:227-233

3. Sheth RA, Sabir S, Krishnamurthy S, Avery RK, Zhang YS, Khademhosseini A, et al. Endovascular embolization by transcatheter delivery of particles: past, present, and future. J Funct Biomater. 2017;8:1-12.

4. Inal O, Boz D. Ion exchange resins and applications in pharmaceutical technology. Adv J Pharm Life Sci Res. 2015;3:16-27.

5. Makadia HK, Siegel SJ. Poly lactic-co-glycolic acid (PLGA) as biodegradable controlled drug delivery carrier. Polymers (Basel). 2011;3:1377-1397.

6. Chai F, Sun L, He X, Li J, Liu Y, Xiong F, et al. Doxorubicin-loaded poly (lactic-co-glycolic acid) nanoparticles coated with chitosan/alginate by layer by layer technology for antitumor applications. Int J Nanomedicine. 2017;12:1791-1802.

7. Azad Khan AK, Howes DT, Piris J, Truelove SC. Optimum dose of sulphasalazine for maintenance treatment in ulcerative colitis. Gut. 1980;21:232-240.

8. Lo M, Ling V, Low C, Wang YZ, Gout PW. Potential use of the antiinflammatory drug, sulfasalazine, for targeted therapy of pancreatic cancer. Curr Oncol. 2010;17:9-16.

9. Singh I, Kumar P, Nagpal M, Arora S. Ion-exchange resin complexation: masking the bitter taste of cefuroxime axetil. Rev Cubana de Farm. 2011;45:171-180.

10. Mensah-Biney R, Reid KJ, Hepworth MT. The loading capacity of selected cation exchange resins and activated carbons for gold-thiourea complex. Miner Eng. 1995;8:125-146.

11. Anand V, Kandarapu R, Garg S. Ion-exchange resins: carrying drug delivery forward. Drug Discov Today. 2001;6:905-914.

12. Kaushik D. Development of taste masked levofloxacin oral suspension using ion exchange resinates. J Chem Pharm Res. 2016:8:385-394.
13. Obeidat WM, Price JC. Evaluation of enteric matrix microspheres prepared by emulsion-solvent evaporation using scanning electron microscopy. J Microencapsul. 2004;21:47-57.

14. Yadav AV, Shete AS, Dabke AP, Shinde VR. Formulation and in-vitro evaluation of aceclofenac microcapsules. Int J PharmTech Res. 2009;1: $135-138$.

15. Jyothi NV, Prasanna PM, Sakarkar SN, Prabha KS, Ramaiah PS, Srawan GY. Microencapsulation techniques, factors influencing encapsulation efficiency. J Microencapsul. 2010;27:187-197.

16. Jafari SM, Assadpoor E, He Y, Bhandari B. Encapsulation efficiency of food flavours and oils during spray drying. Drying Technol. 2008;26:816-835.

17. Dhakar RC, Maurya SD, Sagar BPS, Bhagat S, Prajapati SK, Jain CP. Variables influencing the drug entrapment efficiency of microspheres: a pharmaceutical review. Pharm Lett. 2010;2:102-116.

18. Yan J, Wang F, Chen J, Liu T, Zhang T. Preparation and characterization of irinotecan loaded cross-linked bovine serum albumin beads for liver cancer chemoembolization therapy. Int J Polym Sci. 2016;1:1-8.

19. Kippax P. Appraisal of the laser diffraction particle-sizing technique. Pharm Technol. 2005;29:88-96.

20. Prakash K, Raju PN, Shanta KK, Lakshmi MN. Preparation and characterization of lamivudine microcapsules using various cellulose polymers. Trop J Pharm Res. 2007;6:841-847.

21. Lee SY, Choi JW, Lee JY, Kim DD, Kim HC, Cho HJ. Hyaluronic acid/ doxorubicin nanoassembly-releasing microspheres for the transarterial chemoembolization of a liver tumor. Drug Deliv. 2018;25:1472-1483.

22. Sharma KV, Bascal Z, Kilpatrick H, Ashrafi K, Willis SL, Dreher MR, et al. Longterm biocompatibility, imaging appearance and tissue effects associated with delivery of a novel radiopaque embolization bead for image-guided therapy. Biomaterials. 2016;103:293-304.

23. Zhou X, Kong M, Cheng XJ, Feng C, Li J, Li JJ, et al. In vitro and in vivo evaluation of chitosan microspheres with different deacetylation degree as potential embolic agent. Carbohydr Polym. 2014;113:304-313. 
24. Wikströms. Sephadex ${ }^{\circledast}$ ion exchange media. Edition AA Data file ion exchange chromatography 2007:1-8

25. Irwin Wj, Belaid KA, Alphar HO. drug delivery By ion exchange resin Part III- interaction of ester prodrugs of propranolol with cation exchange resin. Drug Dev Ind Pharm. 1987;13:2047-2066.

26. Srikanth MV, Sunil SA, Rao NS, Uhumwangho MU, Ramana Murthy KV. Ionexchange resins as controlled drug delivery carriers. J Sci Res. 2010;2: 597-611.

27. Banerjee S, Siddiqui L, Bhattacharya SS, Kaity S, Ghosh A, Chattopadhyay P, et al. Interpenetrating polymer network (IPN) hydrogel microspheres for oral controlled release application. Int J Biol Macromol. 2012;50:198-206.

28. Othman M, Ariff AB, Kapri MR, Rios-Solis L, Halim M. Growth enhancement of probiotic Pediococcus acidilactici by extractive fermentation of lactic acid exploiting anion-exchange resin. Front Microbiol. 2018;9:2554.

29. Alexandridou S, Kiparissides C. Production of oil-containing polyterephthalamide microcapsules by interfacial polymerization. An experimental investigation of the effect of process variables on the microcapsule size distribution. J Microencapsul 1994;11:603-614.

30. Mukkala BVP, Tegk M. Studies on influence of process variables on performance of gliclazide mucoadhesive microcapsules. Asian J Pharm Clin Res. 2011;5:167-174.

31. Chella N, Yada KK, Vempati R. Preparation and evaluation of ethyl cellulose microspheres containing diclofenac sodium by novel W/O/O emulsion method. J Pharm Sci Res. 2010;2:884-888.

32. Jelvehgari M, Hassanzadeh D, Kiafar F, Loveym BD, Amin S. Preparation and determination of drug-polymer interaction and in-vitro release of mefenamic acid microspheres made of cellulose acetate phthalate and/or ethylcellulose polymers. Iran J Pharm Res. 2011;10:457-467.
33. Jelvehgari M, Nokhodchi A, Rezapour M, Valizadeh $H$. Effect of formulation and processing variables on the characteristics of tolmetin microspheres prepared by double emulsion solvent diffusion method. Indian J Pharm Sci. 2010;72:72-78

34. Nepal PR, Chun MK, Choi HK. Preparation of floating microspheres for fish farming. Int J Pharm Sci. 2007;341:85-90.

35. Swaine T, Tang Y, Garcia P, John J, Waters LJ, Lewis AL. Evaluation of ion exchange processes in drug-eluting embolization beads by use of an improved flow-through elution method. Eur J Pharm Sci. 2016;93: 351-359.

36. Aman RM, Meshali MM, Abdelghani GM. Ion-exchange complex of famotidine: sustained release and taste masking approach of stable liquid dosage form. Drug Discov Ther. 2014;8:268-275.

37. Samprasit W, Akkaramongkolporn P, Ngawhirunpat T, Rojanarata T, Opanasopit P. Meloxicam taste-masked oral disintegrating tablet with dissolution enhanced by ion exchange resins and cyclodextrin. AAPS PharmSciTech. 2013;14:1118-1128.

38. Akbarzadeh A, Mikaeili H, Zarghami N, Mohammad R, Barkhordari A, Davaran S.Preparation and in vitro evaluation of doxorubicin-loaded $\mathrm{Fe}_{3} \mathrm{O}_{4}$ magnetic nanoparticles modified with biocompatible copolymers. Int J Nanomed. 2012;7:511-526.

39. Kapoor DN, Bhatia A, Kaur R, Sharma R, Kaur G, Dhawan S. PLGA: a unique polymer for drug delivery. Ther Deliv. 2015;6:41-58.

40. Choi JW, Park JH, Cho HR, Chung JW, Kim DD, Kim HC, et al. Sorafenib and 2,3,5-triiodobenzoic acid-loaded imageable microspheres for transarterial embolization of a liver tumor. Sci Rep. 2017;7:554

41. Saralidze K, Koole LH, Knetsch MLW. Polymeric microspheres for medical applications. Materials (Basel). 2010;3:3537-3564.

This work is licensed under a Creative Commons Attribution-NonCommercial 3.0 Unported License which allows users to read, copy, distribute and make derivative works for non-commercial purposes from the material, as long as the author of the original work is cited properly. 